\title{
The Role of Wind Generation in Enhancing Scotland's Energy Diversity and Security
}

\author{
A Mean-Variance Portfolio Optimization of \\ Scotland's Generating Mix
}

\author{
Shimon Awerbuch ${ }^{*}$, In collaboration with Jaap C. Jansen and \\ Luuk Beurskens ${ }^{* *}$
}

s0010

p0010

The UK Energy White Paper sets targets for decarbonization and the deployment of wind and other renewable electricity generating alternatives. The Scottish Executive is committed to increasing renewable energy shares in order to progress on the White Paper objectives. Fossil fuel independence, reliance on domestic sources and enhanced energy security are additional motivating factors for these objectives. Much to its credit, the Scottish Executive is pushing forward with the adoption of wind and other renewables in spite of the widespread belief that these technologies cost more and that increasing their share of the generating mix must therefore increase overall generating costs. The Executive's efforts are especially notable since risk and other externalities, as subsequently discussed, tend to drive market participants to overinvest in fossil technologies relative to wind. The idea that a more costly technology in the mix must raise overall generating cost may seem obvious and compelling. Nonetheless, it is flawed. Energy planning represents an investment decision problem. Investors commonly apply portfolio theory to manage risk and maximize portfolio performance under a variety of unpredictable economic outcomes. This report describes essential portfolio theory ideas and discusses their application to Scotland's electricity generating mix. The report illustrates how wind and other renewables can benefit the Scottish generating mix. Efficient generating portfolios include greater shares of wind, which enhance energy security and also reduce overall

*SPRU Energy Research Group, University of Sussex, Brighton, UK

${ }^{* *}$ ECN - Energy Research Centre of the Netherlands Petten, The Netherlands

Analytical Methods for Energy Diversity and Security @ 2009 Elsevier Science (USA).

978-0-08-056887-4 All rights reserved. 
generating cost. The optimal results indicate that compared to National Grid projected mixes, there exist generating mixes with larger wind shares at equal or lower expected cost and risk.

s0020

p0020

p0030

p 0040 low-risk, passive, capital-intensive technologies. ing portfolio. interpreted as 'Don't put all your eggs in one basket'.

\subsection{Least-cost versus portfolio-based approaches in generation planning}

Wind and other renewables provide clean generating alternatives, and hence offer an effective climate change mitigation mechanism. Yet policy makers are concerned because of the widespread perception that increasing the deployment of wind will raise the overall cost of generating electricity.

Electricity policy and capacity planning are largely conceived using least-cost principles, under which policy makers evaluate generating alternatives using their stand-alone costs. These approaches consistently bias in favour of risky fossil alternatives, while understating the true value of wind and similar fixed-cost,

Today's dynamic and highly uncertain future requires better techniques that reflect market risk. Financial investors know that a diversified asset portfolio provides the best means of hedging risk. Given today's uncertainty about future technology cost and performance, it makes sense also to shift electricity policy and planning from its current emphasis of evaluating alternative technologies, to evaluating alternative generating portfolios and strategies. Mean-variance portfolio (MVP) theory, an established part of modern finance theory, is highly suited to the problem of planning and evaluating Scotland's electricity generat-

MVP evaluates generating alternatives not on the basis of their stand-alone cost, but on the basis of their portfolio cost, i.e. their contribution to overall portfolio generating cost relative to their contribution to overall portfolio risk. At any given time, some alternatives in the portfolio may have higher costs while others have lower costs, yet over time, the astute combination of resources serves to minimize overall expected generation cost relative to the risk. This report describes an MVP-based analysis that examines the effect of increasing the share of wind generation in Scotland. The results suggest that Scotland's electricity generating mix will benefit from additional wind shares, even under an assumption that it costs more than other alternatives on a stand-alone basis.

Although counterintuitive, the idea that adding more costly wind can actually reduce portfolio-generating cost is consistent with basic finance theory and derives from the fact that wind generating costs do not correlate, or co-move with fossil prices. Wind generating costs are essentially fixed or riskless over time and are independent of fossil fuel fluctuations Adding wind therefore helps to diversify the generating mix and enhance its cost-risk performance. The operating costs of a generating mix containing 30\% wind will fluctuate a lot less year-to-year than one with no wind. This idea, which most investors intuitively understand, is widely 
s0030

p0070

p0080

s0040 p0090

\subsubsection{Portfolio-based planning for electricity generation}

Portfolio optimization focuses on generating costs and their risk. Future fossil fuel and other outlays are random statistical variables that move unpredictably over time. No one knows for sure what the price of gas will be next year, just like nobody knows what the stock markets will do. Estimating the generating cost of a particular portfolio presents the same problems as estimating the expected return to a financial portfolio. It involves estimating cost from the perspective of its market risk.

Portfolio optimization locates generating mixes with the lowest expected cost at every level of risk. Risk is measured in the standard finance fashion as the year-to-year variability ${ }^{1}$ of technology generating costs. The projected year 2010 generating mix developed by the National Grid Transco (NGC) serves as a benchmark or target starting point. The optimized results indicate that it is possible to improve on the cost-risk properties of the NGC 2010 mix, i.e. there exist other mixes with larger wind shares that exhibit equal or lower expected cost and risk levels.

\subsubsection{Current and projected Scotland capacity}

Most of Scotland's capacity growth is projected to be in the form of onshore wind (Figure 7.1), which provides Scotland with an opportunity to diversify its mix away from fossil generation. The NGC projected 2010 capacity mix includes $4.1 \mathrm{GW}$ of new onshore wind, which combined with existing wind capacity, totals $5.4 \mathrm{GW}$ of onshore wind. Though significant, it exploits less than half of Scotland's sizeable $11.5 \mathrm{GW}$ wind resource, more than the country's total 2004 generating capacity of $10.5 \mathrm{GW}$.

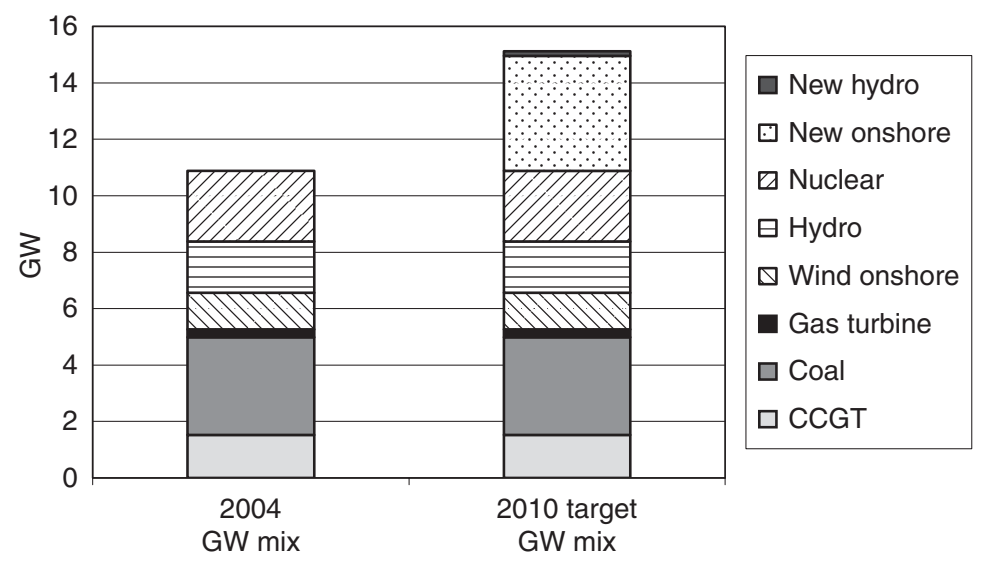

f0010 FIGURE 7.1 Current and projected generating capacity for Scotland. CCGT: combined cycle gas turbine.

${ }^{1}$ Measured as the statistical standard deviation. 


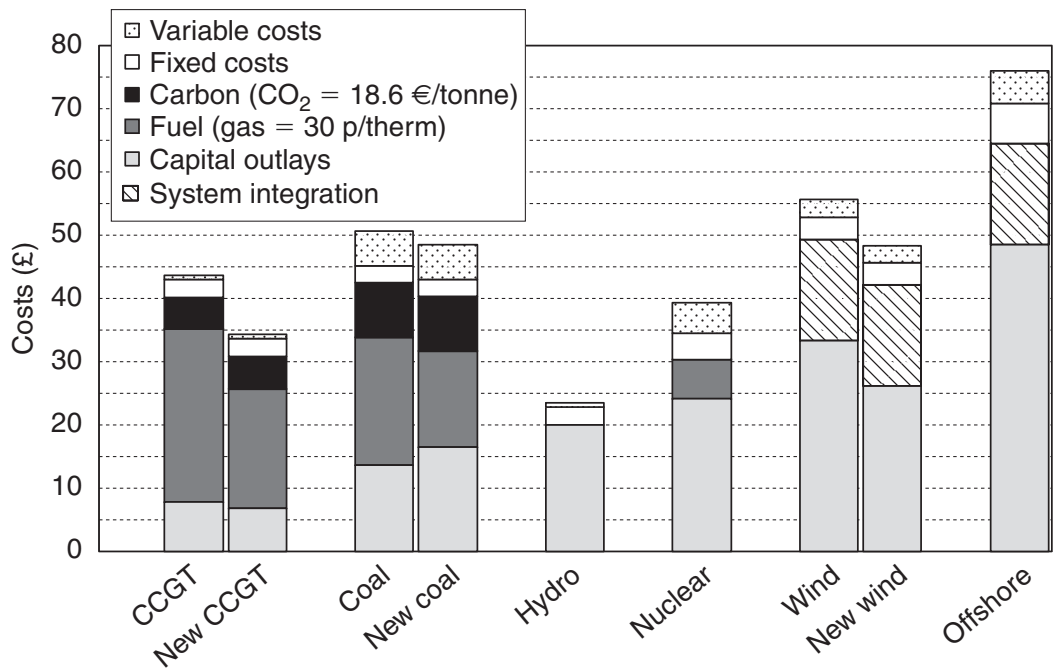

\subsubsection{Technology generating cost} widely cited NGC study (Dale et al., 2004).

\subsection{Portfolio optimization of Scotland's generating mix}

Figure 7.2 shows generating costs for existing capacity as well as new entrants New entrant costs are based on figures provided by Credit Suisse-First Boston $(C S F B, 2005){ }^{2}$ Natural gas price has been revised from CSFB's $27.0 \mathrm{p} /$ them therm to $30.3 \mathrm{p} /$ therm, which is still well below recent levels. The cost of carbon dioxide $\left(\mathrm{CO}_{2}\right)$ has also been revised from CSFB's $€ 15 /$ tonne to $€ 18.6 /$ tonne, again, below recent price levels. Embedded generation costs are based on these adjusted CSFB costs, but are further adjusted to reflect fuel efficiencies and construction cost differences between old- and new-generation technologies. CSFB does not include system integration costs for wind, which are estimated at $£ 16 / \mathrm{MWh}$ based on a

Portfolio optimization compares the risk-return properties of the projected NGC target mix to a set of optimal portfolios that minimize cost and risk. The results indicate that wind diversifies the mix without raising cost, in spite of the fact that its assumed stand-alone cost (Figure 7.2) exceeds that of other new entrants.

Portfolio optimization does not advocate for particular generating mixes, but rather displays the risk-cost tradeoffs among various mixes. The results of the

${ }^{2}$ Off-shore wind costs provided by Airtricity. All generating costs expressed in terms of $£ / \mathrm{MWh}$, which can be divided by 1000 to obtain the equivalent $\mathrm{p} / \mathrm{kWh}$ cost. 
analysis presented here are illustrative in the sense that they do not represent a specific capacity expansion plan and generally ignore any requirement to optimize technologies to the load-duration curve. They are meant to illustrate the so-called portfolio effect: as long as the mix can be reshuffled over time, adding wind and other fixed-cost technologies has the effect of diversifying the generating mix and reducing its expected cost.

p0130 In deregulated environments, investment decisions are make by individual power producers who evaluate only their own direct costs and risks and do not reflect the effects that their technologies may have on overall portfolio performance. Wind investors, for example, cannot capture the risk-mitigation benefits they produce for the generating portfolio, which leads to underinvestment in wind relative to levels that may be more optimal from a customer or societal perspective. Some investors prefer the risk-reward menu offered by fuel-intensive technologies such as combined cycle gas turbine (CCGT), which have very low capital costs. Given sufficient market power, these investors may be able to externalize fuel risks onto customers. In the presence of market power, these investors do not bear the full risk effects they impose onto the generating mix, which may lead to overinvestment in gas relative to what is more optimal from a total portfolio perspective.

The charts accompanying the subsequent discussion show the portfolio generating cost and risk for a number of scenarios. An infinite number of possible mixes exists on each chart, although only a small set of typical mixes is located and shown.

s0070

p0150

s0080 p0160

\subsubsection{The base case}

Expressing technology costs without their market risk means little. Figure 7.3 shows the base-case cost and risk of each existing and new-entrant technology along with the estimated cost-risk of the NGC 2010 target mix. ${ }^{3}$ The chart depicts what is a highly cautious set of costs for onshore and offshore wind. The assumed offshore wind cost, $£ 76 / \mathrm{MWh}$, is nearly $50 \%$ higher than similar costs used in the Netherlands and elsewhere.

\subsubsection{Base-case portfolio optimization results}

Figure 7.4 shows the base-case cost and risk for the NGC target as well as the optimized results. The NGC generating mix has an overall cost of $£ 45.10$ with a risk of $4 \%$. While there exists an infinite number of portfolios with superior costrisk properties, four typical mixes are focused on, located on the efficient frontier, i.e. the location of all optimized portfolios. The NGC mix lies above the efficient frontier. Any generating portfolio that lies below or to the left of the target represents an improvement in cost and risk. For example, mix $\mathrm{N}$ is superior to the target mix. It has the same cost, but lower risk. Mix $\mathrm{S}$ is also more desirable, since it

\footnotetext{
${ }^{3}$ In Figure 7.3, 'Nuclear' represents exiting plant, for which capital investment risk is zero so that total risk reflects primarily fuel and other operating costs. Decommissioning risks and the cost-risk of long-term waste disposal are ignored.
} 
reduces the target's cost by about $6 \%(£ 42.6 / £ 45.1$; Figure 7.4 , table insert) without increasing risk. ${ }^{4}$

p 0170

In the NGC mix, $23 \%$ of total electricity produced comes from onshore wind. Mix N, by comparison, contains $31 \%$ onshore wind plus $2 \%$ offshore wind, in

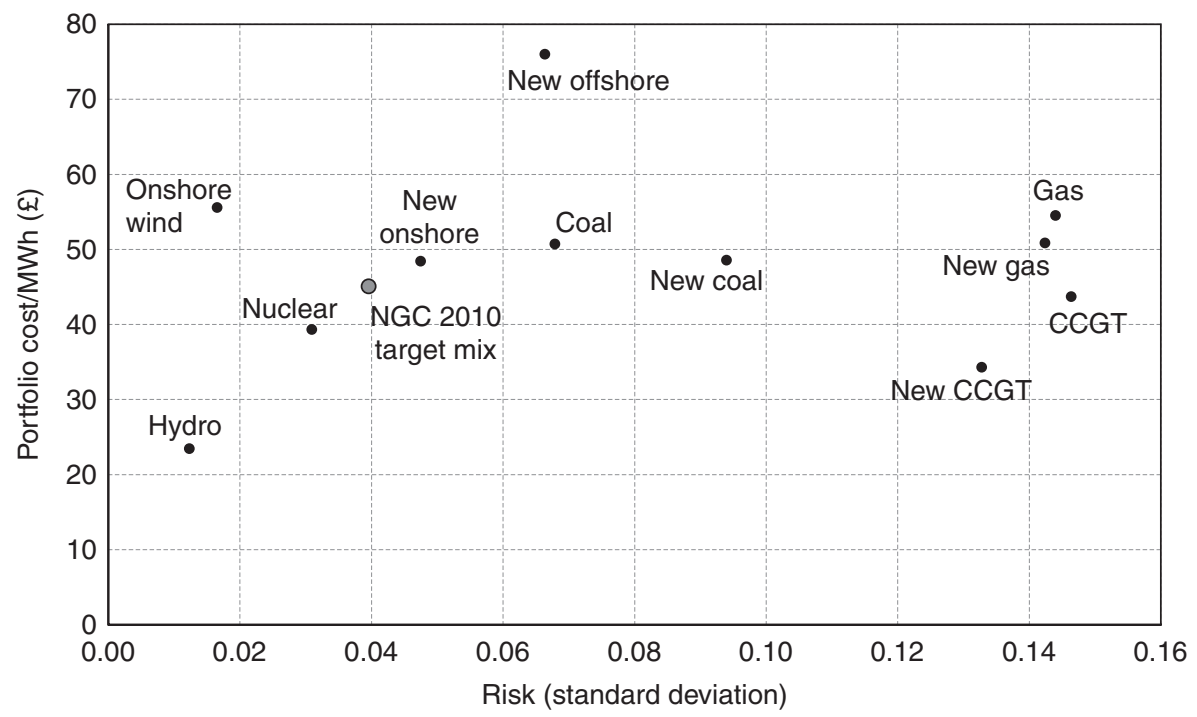

f0030 FIGURE 7.3 Base-case technology cost and risk. CCGT: combined cycle gas turbine.

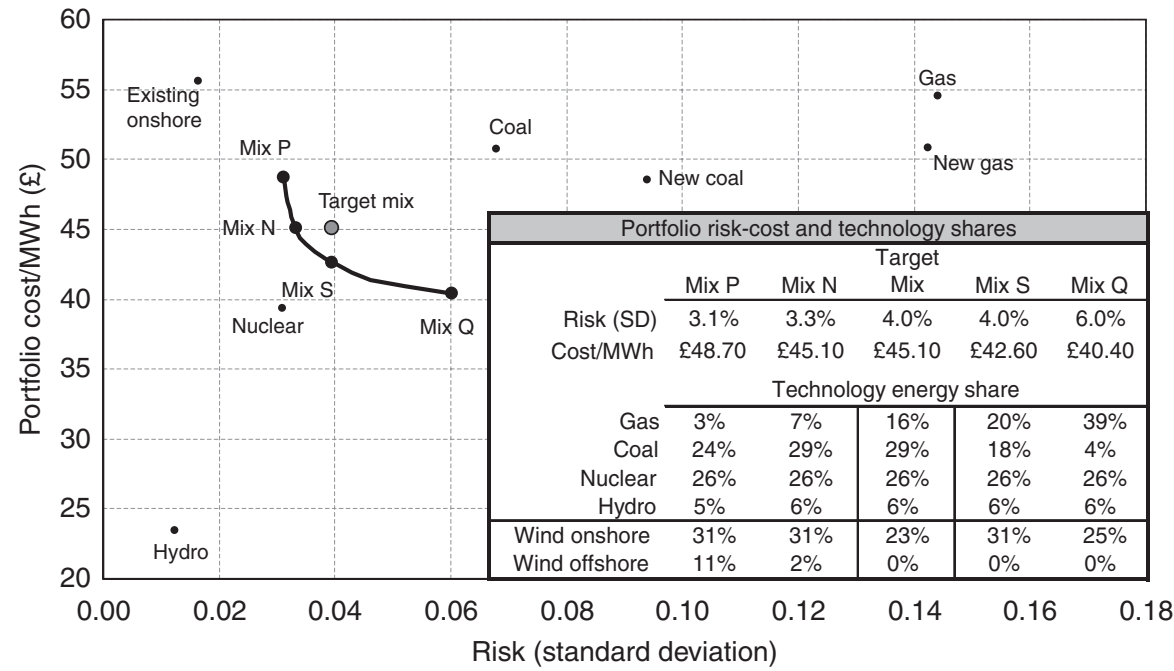

f0040 FIGURE 7.4 Base-case optimized portfolio results.

${ }^{4}$ Nuclear is constrained to its 2004 level, which equates to $26 \%$ of total generation in 2010 . 
spite of the fact that wind costs more than new gas. Mix $\mathrm{P}$, which costs about $0.5 \mathrm{p} / \mathrm{kWh}$ more than the target, contains $11 \%$ offshore wind. These typical mixes would no doubt contain larger wind shares were it not for an arbitrary constraint imposed on the results: onshore wind was limited to two-thirds of Scotland's total available resource. At this level of penetration onshore wind represents $31 \%$ of the total mix.

s0090

p0180

p0190

\subsubsection{Case II: accelerated (minimum 10\%) offshore wind deployment}

In the base case, mix $\mathrm{S}$ (and $\mathrm{Q}$ ) contains no offshore wind and mix $\mathrm{N}$ contains only a minimal amount. Portfolio theory suggests that other mixes that do contain offshore wind are likely to exist at the same risk level. These mixes are located by searching for optimized solutions that include a given minimum offshore wind share. This minimum wind share is arbitrarily set to $10 \%$. The results (Figure 7.5) indicate that increasing offshore wind to at least $10 \%$ of the mix leaves the costs of mix $\mathrm{P}$ and mix $\mathrm{N}$ unchanged, although the risk of mix $\mathrm{N}$ rises to $4 \%$, i.e. mix $\mathrm{N}$ shifts to the right from its base-case risk of $3.3 \%$, so it is virtually co-located with the NGC target mix.

Accelerating offshore wind in this manner also raises the cost of mix $\mathrm{S}$ by about $0.25 \mathrm{p} / \mathrm{kWh}$, from $£ 42.6 / \mathrm{MWh}$ in the base case to $£ 45.1 / \mathrm{MWh}$ in Figure 7.5. Mix S is therefore now also virtually co-located with mix N and with the NGC target. In general, therefore, accelerating offshore wind to $10 \%$ of the mix produces only minimal cost-risk effects on the overall generating system. While the cost-risk of mixes $\mathrm{N}$ and $\mathrm{S}$ is almost identical to the NGC target, their technology

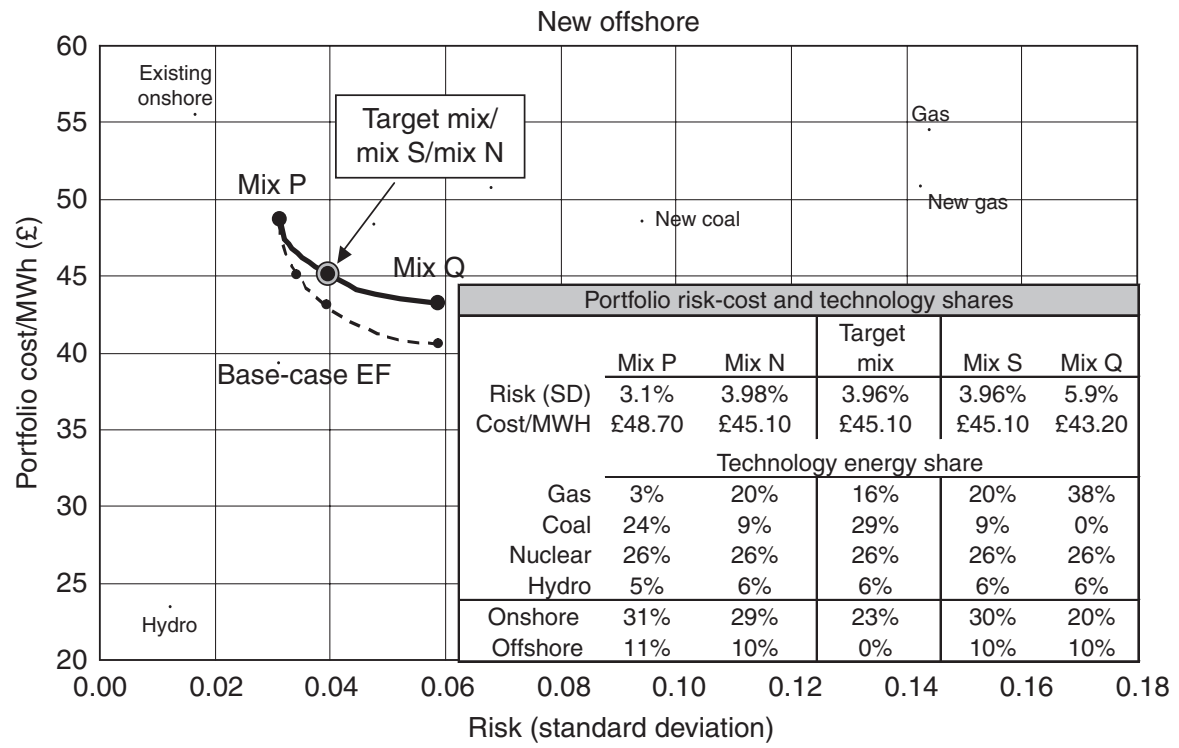

f0050 FIGURE 7.5 Portfolio cost and risk: accelerated offshore wind case. 
makeup differs. Mixes $\mathrm{N}$ and $\mathrm{S}$ comprise essentially identical technology shares, which include $10 \%$ offshore wind along with about $30 \%$ onshore wind. The total wind share of these optimized mixes is therefore $40 \%$, as compared to $23 \%$ for the NGC target (which contains no offshore wind). The results of this case therefore indicate that offshore wind can be increased to at least $10 \%$, without raising costrisk relative to the NGC target. The cost of this move relative to the base case is a minimal $0.25 \mathrm{p} / \mathrm{kWh}$.

s0100

p0200

p0210

\subsubsection{Case III: higher 'current outlook' natural gas prices}

This case balances highly cautious wind assumptions with higher assumed natural gas prices, which are now taken as $40 \mathrm{p} /$ therm, the approximate current cost of a four-year forward. Since $\mathrm{CO}_{2}$ cost is correlated with natural gas prices, its value is also raised to €24/tonne (Figure 7.6). System charges remain unchanged at $£ 16 / \mathrm{MWh}$ of wind output.

Under the assumptions of this case, generating costs for NGC target mix rise to $£ 47.5$ from $£ 45.1$ in the base case. ${ }^{5}$ Similar cost increases are observed for the four typical mixes, which now generally contain smaller gas generation shares (Table 7.1). As for the previous cases, the optimized mixes $\mathrm{N}$ and $\mathrm{S}$ show a superior cost-risk relative to the target mix. Optimized onshore wind shares remain unchanged from the base case, ${ }^{6}$ although offshore wind increases in mixes $\mathrm{P}$ and $\mathrm{N}$.

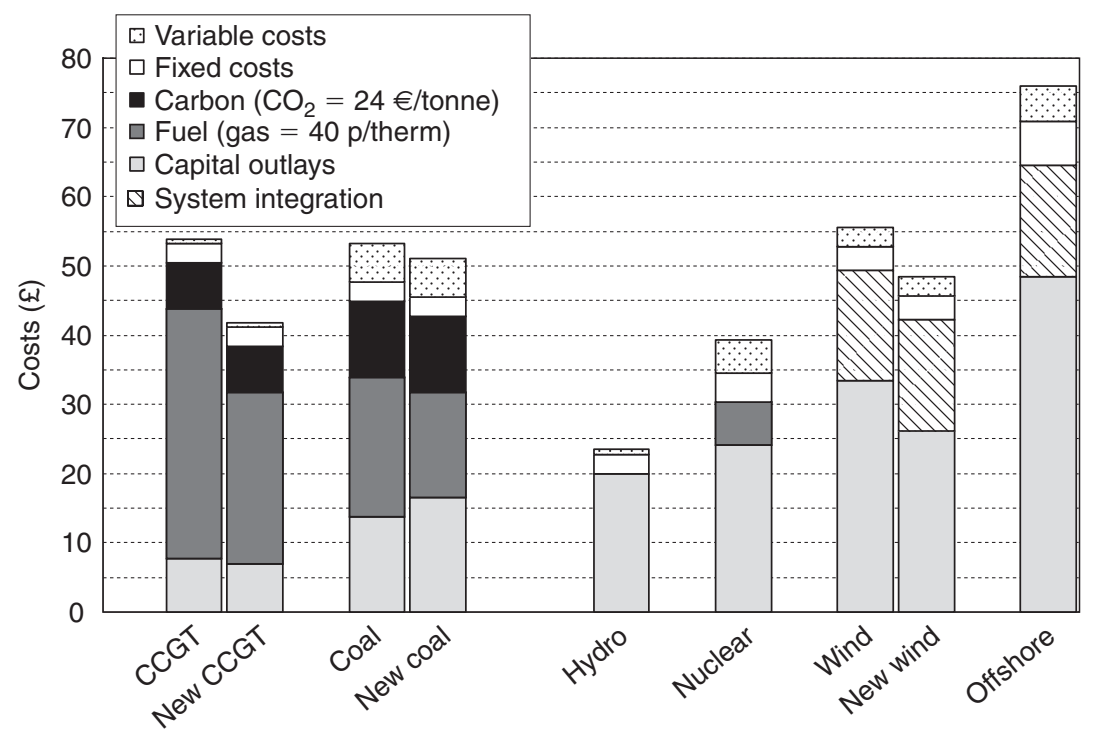

f0060 FIGURE 7.6 Technology costs for 'outlook gas' case.

${ }^{5}$ Target mix costs did not change for the accelerated offshore wind case.

${ }^{6}$ Onshore wind is already at its maximum limit, the exception being mix $Q$, where onshore wind remains at $25 \%$. 
s0110

p0220

p0230

t0010

\subsubsection{The basis for a 'no regrets' Scottish wind policy}

Figure 7.7 compares the range of optimal solutions for Case III ('current outlook' natural gas prices) with those of Case II, accelerated offshore wind. The efficient frontier (the location of optimal mixes) for these two cases is very similar. This suggests that if gas prices remain at current levels, it makes considerable economic sense for the Scottish Executive to pursue policy options that accelerate offshore wind deployment.

The message of the analysis therefore is that with current market expectations, a mix such as $\mathrm{N}$, which contains $5 \%$ offshore wind (Table 7.1), represents a 'no regrets' policy: it costs no more than the target mix yet it lowers risk. If

Table 7.1 Case III: Outlook gas portfolio details

\begin{tabular}{lccccc}
\hline & Mix P & Mix N & Target mix & Mix S & Mix Q \\
\hline Risk (SD) & $3.2 \%$ & $3.3 \%$ & $4.1 \%$ & $4.1 \%$ & $5.1 \%$ \\
\hline Cost/MWh & $£ 49.80$ & $£ 47.50$ & $£ 47.50$ & $£ 44.50$ & $£ 43.50$ \\
\hline \multicolumn{5}{c}{ Technology energy share } \\
\hline Gas & $2 \%$ & $4 \%$ & $16 \%$ & $20 \%$ & $25 \%$ \\
\hline Nuclear & $23 \%$ & $29 \%$ & $29 \%$ & $18 \%$ & $18 \%$ \\
\hline Hydro & $26 \%$ & $26 \%$ & $26 \%$ & $26 \%$ & $26 \%$ \\
\hline Wind onshore & $5 \%$ & $6 \%$ & $6 \%$ & $6 \%$ & $6 \%$ \\
\hline Wind offshore & $13 \%$ & $31 \%$ & $23 \%$ & $31 \%$ & $25 \%$ \\
\hline
\end{tabular}

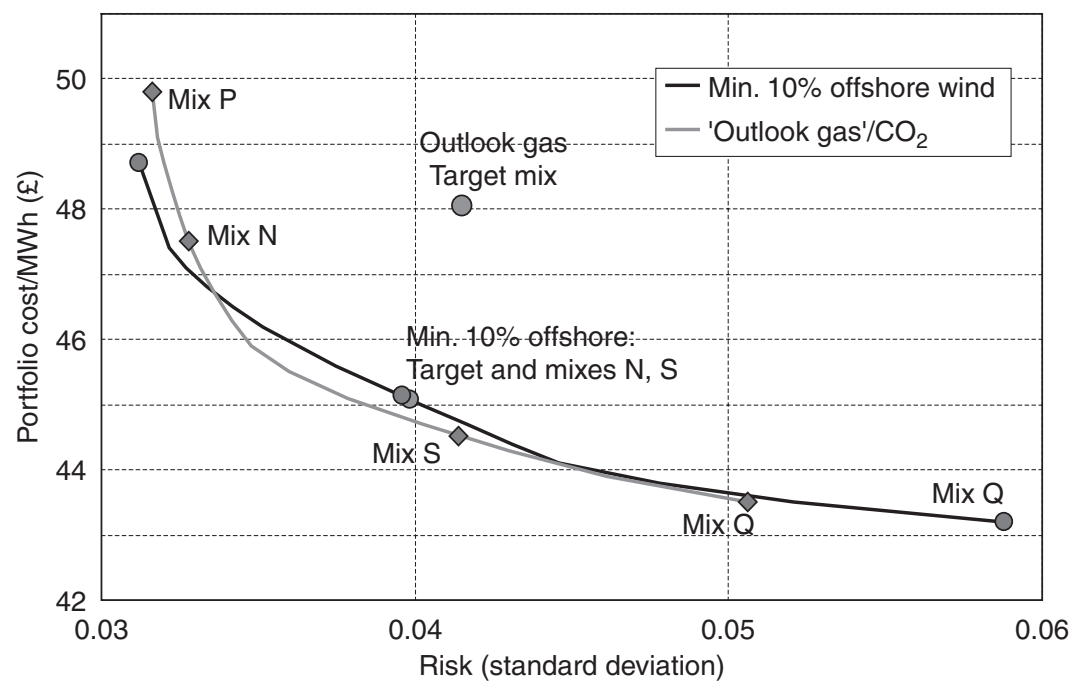

f0070 FIGURE 7.7 Optimal solutions: cases II and III. 


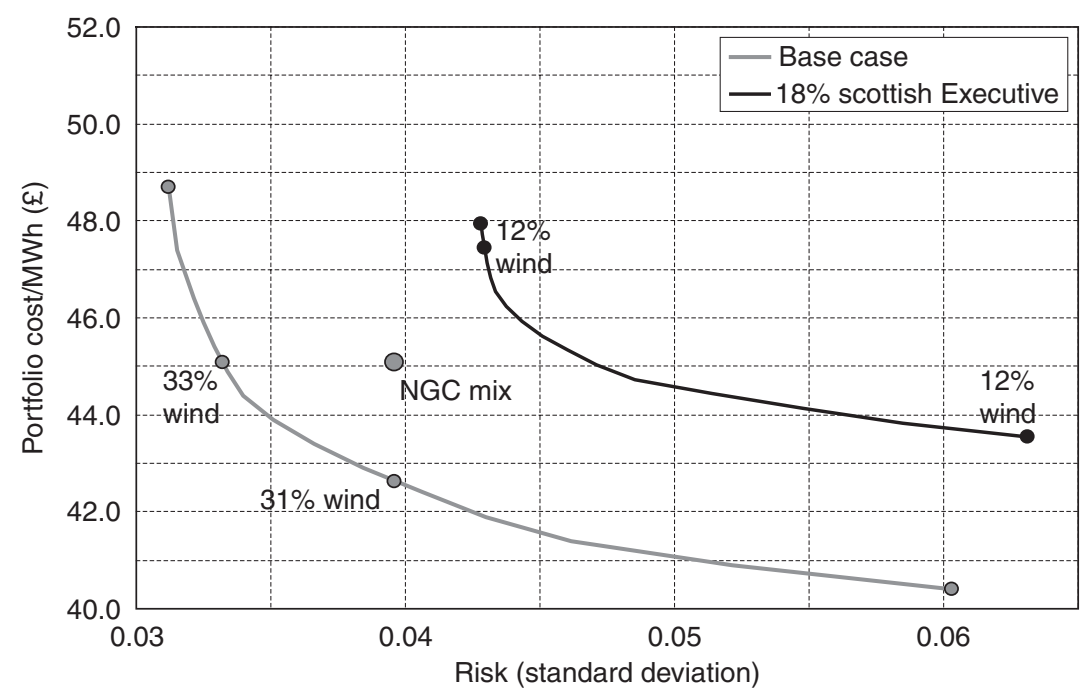

FIGURE 7.8 Cost-risk for Scottish Executive 2010 renewables target.

expected high gas prices are sustained, a Scotland mix consisting of about $31 \%$ onshore wind and $10 \%$ offshore wind will generally outperform the NGC target mix and will perform at least as well as other mixes with less wind.

s0120 p0240

p 0250

\subsubsection{The cost of not fully exploiting Scotland's onshore wind potential}

The Scottish Executive has set a 2010 renewables target of 18\% of electricity generated (Scottish Executive, 2001). Hydro shares represent about 6\% of generation, so that the Executive's target effectively implies a $12 \%$ goal for wind. Lower wind shares generally increase cost-risk. Indeed, relative to the base case, limiting wind to the Executive's 12\% target raises cost and risk significantly (Figure 7.8).

While the Scottish Executive has set targets, not limits, the message of the analysis is clear: failing to exploit Scotland's wind resources significantly raises cost and risk.

\subsection{Conclusions: implications for Scotland's capacity planning}

Today's dynamic and uncertain energy environment requires portfolio-based techniques that reflect market risk and de-emphasize stand-alone generating costs. MVP theory is well tested and ideally suited to evaluating national electricity strategies. It helps to identify solutions that enhance energy diversity and security and are therefore more robust than arbitrarily mixing technology alternatives.

Portfolio analysis reflects the cost interrelationship (covariances) among generating alternatives, which is crucial for correctly evaluating generating portfolios. The analysis described here does not represent or advocate for a particular 
capacity expansion plan. Rather, its purpose is to demonstrate that increasing the share of wind in Scotland generally lowers overall generating costs, even if it believed that wind costs more than gas. The results suggest that the NGC $2010 \mathrm{mix}$, although it reflects relatively significant wind shares, may not go far enough. Larger wind shares appear to insulate better the generating mix from systematic risk of gas (and coal) price movements, which have historically been quite correlated.

p0280 This report presents a series of optimized portfolio results for several scenarios, using a highly cautious set of cost estimates for wind. It compares these optimized portfolios to the NGC-2010 generating mix, which projects an onshore wind share of $23 \%$ and offshore wind of $0 \%$. The optimized results presented here strongly suggest that without increasing cost or risk, onshore wind can be increased to at least $31 \%$ of electricity generation: half again as much as the NGC target and nearly 75\% more than envisioned by the Scottish Executive's 2010 targets. Even with a highly cautious cost of $£ 76 / \mathrm{MWh}$ (compared to gas at $30 \mathrm{p} /$ therm) offshore wind shares can rise to at least to as much as 10\% (2GW of capacity) without increasing cost.

p0290 Moreover, if natural gas prices remain in the range of $40 \mathrm{p} /$ therm, as futures prices indicate, a mix of about $31 \%$ onshore and $10 \%$ offshore wind provides the basis for a no-regrets wind policy for Scotland. The evidence suggests that this mix will outperform the NGC-2010 mix and will perform at least as well as other portfolios with less wind.

p0300 Against this backdrop, the Scottish Executive 18\% 2010 renewables targets may not be sufficiently aggressive. Indeed, the analysis indicates that reducing wind shares from their optimized levels (31\% onshore, $5-10 \%$ offshore) significantly increases the cost and the risk of the Scottish mix.

p0310 In deregulated environments, investment decisions are made by individual power producers who evaluate only their own direct costs and risks, but do not reflect the effects that their technologies may have on overall generating portfolio performance. For example, wind investors cannot capture the risk-mitigation benefits they produce for the overall portfolio, which leads to underinvestment in wind relative to societally optimal levels. Some investors, however, may prefer the risk menu offered by fuel-intensive gas CC turbines, which have low initial costs. Given sufficient market power, these investors may be able to externalize fuel risks onto customers so that they do not bear the full risk effects they impose onto the generating mix. This would lead to overinvestment in gas relative to what is more optimal from a portfolio or societal perspective.

p0320 Given the high degree of uncertainty about future energy prices, the relative value of generating technologies must be determined not by evaluating alternative resources, but by evaluating alternative resource portfolios. Energy analysts and policy makers face a future that is technologically, institutionally and politically complex and uncertain. In this environment, MVP techniques help to establish renewables targets and portfolio standards that make economic and policy sense. They also provide the analytical basis that policy makers need to devise efficient generating mixes that maximize security and sustainability. MVP analysis shows that contrary to widespread belief, attaining these objectives need 
not increase cost. In the case of Scotland, increasing the share of wind, even if it is believed to cost more on a stand-alone basis, reduces portfolio cost-risk and enhances energy security.

\section{References}

Credit Suisse-First Boston (2005). Electricity Handbook, Vol. 10 (20 July).

Dale, L., Milborrow, D., Slark, R. and Strbac, G. (2004). Total cost estimates for large-scale wind scenarios in UK, Energy Policy, 32.

Scottish Executive (2001) Scotland's Renewable Energy Potential Beyond 2010: A Consultation Paper. www. scotland.gov.uk/library5/environment/renewenergy2010.pdf

\section{Further reading}

Awerbuch, S. (2000). Getting it right: the real cost impacts of a renewables portfolio standard. Public Utilities Fortnightly(15 February).

Awerbuch, S. (2005). Portfolio-based electricity generation planning: policy implications for renewables and energy security. Mitigation and Adaptation Strategies for Global Change (in press).

AUQ1

Awerbuch, S. and Berger, M. (2003). Energy Security and Diversity in the EU: A Mean-Variance Portfolio Approach. IEA Report No. EET/2003/03. Paris: International Energy Agency (February). http:// library.iea.org/dbtw-wpd/textbase/papers/2003/port.pdf

Berger, M. (2003). Portfolio Analysis of EU Electricity Generating Mixes and Its Implications for Renewables. Ph.D. Dissertation, Technischen Universität Wien, Vienna (March).

Bolinger, M., Wiser, R. and Golove, W. (2004). Accounting for fuel price risk when comparing renew-

AUQ2 able to gas-fired generation: the role of forward natural gas prices. Energy Policy.

Fabozzi, F., Gupta, F. and Markowitz, H. (2002). The legacy of modern portfolio theory. Journal of Investing, 11(Fall), 7-22.

Seitz, N. and Ellison, M. (1995). Capital Budgeting and Long-Term Financing Decisions. Dryden Press.

Author Queries

\{AUQ1\} AU: Awerbuch, 2005 (in press): update.

\{AUQ2\} AU: Bolinger et al. (2004): update. 